\title{
Experimental investigations of zones of leakage from damaged water network pipes
}

\author{
M. Iwanek, D. Kowalski, B. Kowalska, E. Hawryluk \\ \& K. Kondraciuk \\ Faculty of Environmental Engineering, \\ Lublin University of Technology, Poland
}

\begin{abstract}
Breakages and damage of pipes in a water network are ordinary challenges for corporations managing distribution systems. The problems of detection and evaluation of a range of leakages have been reported in many publications, but in scientific literature there are relatively few studies on the zones of water leakages caused by the pipe breakages.

The aim of this paper was to evaluate the distance between the site of breakage and the place of the water effluence on the ground surface. The investigations were conducted in the laboratory, on the stand reflecting natural conditions scaled 1:10. Design of the stand was preceded by the dimensional analysis. There were two variable parameters in the investigations: a pipe dimension and a pressure head in the pipe. During the experiment the pipe under internal water pressure was intentionally damaged causing the leakage and next, the place of the water effluence on the ground surface was localized. The effluence rarely occurred directly over the site of the leakage.

The obtained results of the investigations enabled us to determine the secure distance between pipes of a water system and buildings or other infrastructure objects. It is important for the stability of infrastructure objects - a large number of disasters caused by water undermining foundations were reported in the literature. The authors are going to continue the investigations for in-situ conditions and to elaborate the numerical model of the analyzed problem.

Keywords: water supply, leakage, protection zone, damaged pipe, laboratory simulation.
\end{abstract}




\section{Introduction}

Pipe breakages and damage in a water network are ordinary challenges for corporations managing distribution systems. The leakages are the main source of water losses from water distribution systems [1, 2]. A large number of reported accidents of leakages from water pipelines causing interruptions in water supply to houses, damage of roads surface, traffic jams, and thereby generating economical costs, show the scale of the problem.

In urban areas, especially hazardous water leakage effects are those that relate to suffosional process, in which fine soil particles are washed out from the solid matrix and transported through the pores by water flowing in the soil $[3,4]$.They can be a cause of, or contributing factor to, many dangerous situations. In extreme cases building constructions can be threatened. Khomenko [4] reported destruction of a five-storey block of flats in the town of Kurgan (Russia) because of suffosional collapse sink created by water from a damaged water main.

Major incidents of the type noted above are reported from time to time only, and most damage caused by water leakages do not result in catastrophic failures. Although they occur on a small scale, they often cause clearly noticeable adverse effects.

Small leakages (less than $0.25-0.5 \mathrm{~m}^{3} / \mathrm{h}$ at $50 \mathrm{~m}$ water head) are undetectable. Leakages of high flow-rates are readily detected and require immediate attention. Leakages of moderate flow-rates accumulate gradually and are not always quickly repaired [5-7].

A lot of leakage detection methods have been reported in the literature for the recent years (e.g. [8-11]]. Moreover, inspection technologies for condition assessment and detection of structural imperfections of water pipes have been still being developed [12]. It is very important, because early detection of leakage can prevent its adverse effects. However it is not enough way to limit the problem. Even the best systems of leakage detection do not secure against failures occurring randomly.

In our research we propose to create a protection area on the soil surface over a buried water network, called a zone of leakage, where effluence of water is possible after a presumptive failure of the pipe. The width of the zone of leakage would correspond to the secure distance between pipes of a water system and buildings or other infrastructure objects, which is important for the stability of infrastructure objects. Infrastructure and settlement in this zone should be planned so as to limit social, economical and environmental costs in the case of a water network failure.

The aim of this paper is to evaluate the distance between a place of the pipe breakage and a place of the water effluence on the ground surface. The obtained results of the investigations will enable to determine the width of the zone of leakage. 


\section{Material and methods}

The investigations of the zone of a leakage from a damaged water pipe were conducted in the laboratory. Designing of a laboratory stand was preceded by the dimensional analysis, which demonstrated necessity of some simplifications to avoid methodological difficulties during investigations. Thus, we limited application of the dimensional analysis results to the geometric similarity.

The results obtained in the laboratory investigations were statistically analyzed.

\subsection{Laboratory stand}

The laboratory stand (Fig. 1) reflecting natural conditions scaled 1:10, consisted of a water coppery pipe 1 buried in sand filling a box 2 (with dimensions of 1.5 by 1.5 by $0.5 \mathrm{~m}$ ). One end of the pipe 1 sticking out of the box 2 was connected through a hose 3 with valves 4 and 5 to an open container 6 placed at the assumed height and the other end was connected through a valve 7 with a hose 8 directing water to a floor drain. The pipe consisted of two parts connected by a bell-and-spigot joint 9 in the half length of the pipe. A drainage 10 was installed on the bottom of the box 2 to enable outflow of water after experiments.

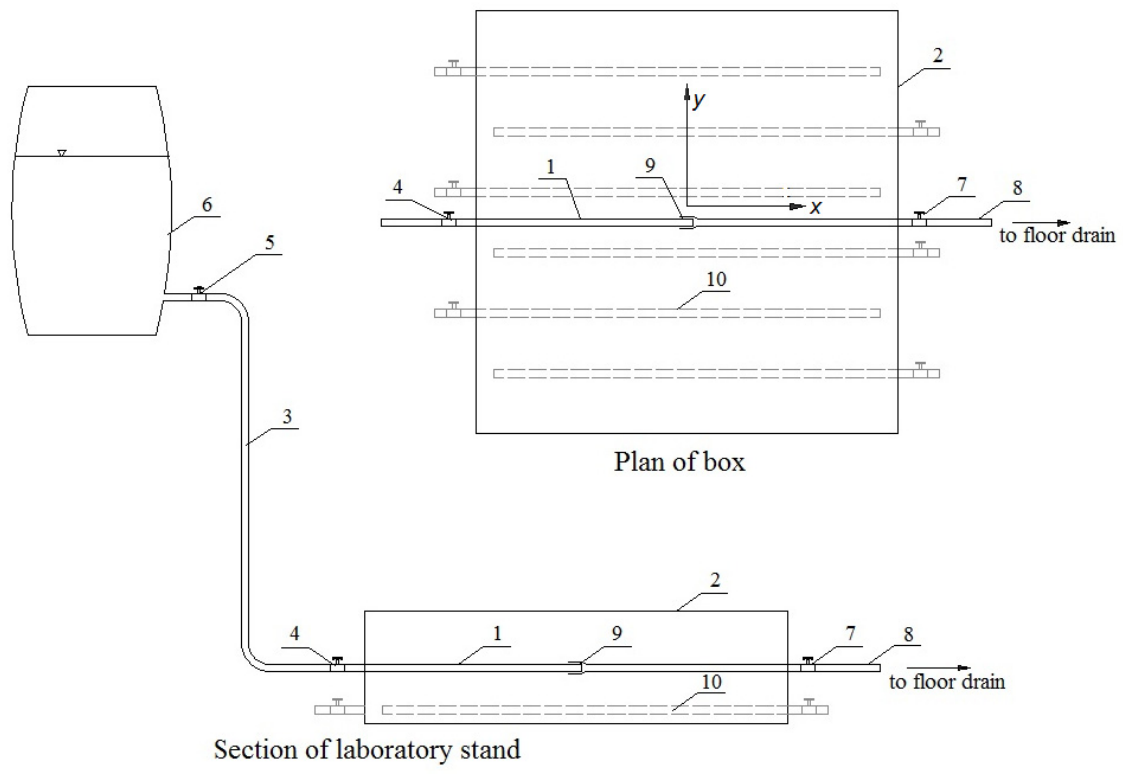

Figure 1: Scheme of laboratory stand.

\subsection{Laboratory investigations}

At first, all valves (Fig. 1) are closed and water is poured into the container 6 above the assumed level. Next, the valves are open and when water in the 
container reaches the assumed level after the deaeration process, the valve 7 is closed. Then two parts of the pipe 1 are disconnected (in the bell-and-spigot joint 9) pulling one end of the pipe 1 sticking out of the box 2 . After the water appears on the sand surface, the valve 4 is closed and the water effluence is localized. All time after a deaeration process the experiment is recorded by a video camera.

The investigations were conducted for 4 pipes $-12,15,22$ or $28 \mathrm{~mm}$ in an outer diameter. Internal water pressure in a pipe varied from 31.9 to $58.8 \mathrm{kPa}$ (from 3.25 to $6.0 \mathrm{~m} \mathrm{H}_{2} \mathrm{O}$ ) - depending on the height of the container 6 place and on the water level in it.

\subsection{Analyses}

The localization of the place of water effluence on the sand surface after a simulated failure was described as a distances $x$ and $y$ between the pipe joint and the place of water effluence on the sand surface: $x$ - parallel to the water pipe and $y$-perpendicular to the pipe.

The results of the laboratory experiment were the basis of univariate analyses. A distance between the pipe joint and the place of water effluence on the sand surface was treated as a single variable, which distribution including a central tendency and a dispersion was assessed. In the range of a central tendency a mean, a mode and a median were evaluated. To assess a dispersion, the range and quartiles of the data set as well as the standard deviation were determined. These parameters were calculated for all $x$ and $y$ data set and for data $x$ and $y$ selected according to a pipe diameter $D$ and an internal water pressure $p$ in a pipe.

The next step in the analysis was evaluation of a zone of leakage from a damaged water pipe. To this end, tolerance intervals were determined with the confidence level of $95 \%$ and $99 \%$ for all $x$ and $y$ data. It was assumed in the calculations that the effluence on the sand surface always occurred on the one side of the place of water leakage from the pipe and only the values of distances $x$ and $y$ were taken to analysis. The result of this simplification is the assumption that the lower tolerance limit always equals 0 independently of the calculations results and the upper tolerance limit corresponds to a half of the width of a zone of leakage from a damaged water pipe.

\section{Results and discussion}

The results of the univariate analysis of the distances $x$ and $y$ conducted for all measurements results are presented in Table 1.

Table 1: $\quad$ Univariate analysis of distances $x$ and $y$.

\begin{tabular}{|c|c|c|c|c|c|c|c|c|c|c|}
\hline \multirow[t]{2}{*}{ Distance } & \multirow{2}{*}{$\begin{array}{l}\text { Number of } \\
\text { measure- } \\
\text { ments }\end{array}$} & \multirow{2}{*}{$\begin{array}{l}\text { Mode } \\
(\mathrm{cm})\end{array}$} & \multicolumn{3}{|c|}{ Distance $(\mathrm{cm})$} & \multirow{2}{*}{$\begin{array}{l}\text { Range } \\
(\mathrm{cm})\end{array}$} & \multicolumn{3}{|c|}{ Quartile (cm) } & \multirow{2}{*}{$\begin{array}{l}\text { Standard } \\
\text { deviation } \\
(\mathrm{cm})\end{array}$} \\
\hline & & & maxima & & & & first & $\begin{array}{l}\text { second } \\
\text { (median) }\end{array}$ & third & \\
\hline$x$ & & 3.20 & & & & & 6.0 & & & \\
\hline$y$ & 111 & 10.60 & 44.00 & 19.71 & 0.00 & 44.00 & 11.00 & 19.00 & 27.00 & 11.07 \\
\hline
\end{tabular}


Statistical distributions of the $x$ and $y$ data were found right asymmetrical, what accounts for a small difference between the mean and the standard deviation values for both $x$ and $y$. The mean is hardly higher than the median and widely higher than the mode for the both cases. Similar data distribution and relations between a mean, a median and a mode were observed during analysis of data $x$ selected according to the pipe diameter for all cases (Tab. 2) and of data $y$ for the pipe diameters of 12 and $15 \mathrm{~mm}$ (Tab. 3). During analysis of data $x$ and $y$ selected according to the internal water pressure, similar relations occurred for 3 cases of a distance $x$ (for the pressure of 4.70, 5.00 and $5.50 \mathrm{~m} \mathrm{H}_{2} \mathrm{O}$ - Tab. 4) and also for 3 cases of a distance $y$ (for the pressure of 4.70, 5.20 and $6.20 \mathrm{~m} \mathrm{H}_{2} \mathrm{O}-$ Tab. 5).

Table 2: $\quad$ Univariate analysis of $x$ distance for different pipe diameter $D$.

\begin{tabular}{|c|c|c|c|c|c|c|c|c|c|c|}
\hline \multirow{2}{*}{$\begin{array}{c}D \\
(\mathrm{~mm})\end{array}$} & \multirow{2}{*}{$\begin{array}{c}\begin{array}{c}\text { Number of } \\
\text { measure- } \\
\text { ments }\end{array} \\
\end{array}$} & \multirow{2}{*}{$\begin{array}{l}\text { Mode } \\
(\mathrm{cm})\end{array}$} & \multicolumn{3}{|c|}{$x(\mathrm{~cm})$} & \multirow{2}{*}{$\begin{array}{l}\text { Range } \\
(\mathrm{cm})\end{array}$} & \multicolumn{3}{|c|}{ Quartile $(\mathrm{cm})$} & \multirow{2}{*}{$\begin{array}{c}\text { Standard } \\
\text { deviation } \\
(\mathrm{cm})\end{array}$} \\
\hline & & & maximal & mean & minimal & & first & $\begin{array}{c}\text { second } \\
\text { (median) }\end{array}$ & third & \\
\hline 12 & 25 & 3.20 & 48.10 & 18.09 & & & 5.00 & 17.00 & 26.00 & 14.62 \\
\hline 15 & 25 & 3.30 & 25.90 & 12.04 & 0.00 & 25.90 & 4.00 & 2.00 & 20.00 & 8.74 \\
\hline 22 & 27 & 2.50 & 50.10 & 20.44 & 0.50 & 49.60 & 10.00 & 20.00 & 30.00 & 14.70 \\
\hline 28 & 26 & 15.00 & 58.00 & 23.23 & 2.10 & 55.90 & 11.00 & 17.50 & 32.00 & 16.24 \\
\hline
\end{tabular}

Table 3: $\quad$ Univariate analysis of $y$ distance for different pipe diameter $D$.

\begin{tabular}{|c|c|c|c|c|c|c|c|c|c|c|}
\hline \multirow{2}{*}{$\begin{array}{c}D \\
(\mathrm{~mm})\end{array}$} & \multirow{2}{*}{$\begin{array}{c}\text { Number o } \\
\text { measure- } \\
\text { ments }\end{array}$} & \multirow{2}{*}{$\begin{array}{l}\text { Mode } \\
(\mathrm{cm})\end{array}$} & \multicolumn{3}{|c|}{$y(\mathrm{~cm})$} & \multirow{2}{*}{$\begin{array}{l}\text { Range } \\
(\mathrm{cm})\end{array}$} & \multicolumn{3}{|c|}{ Quartile $(\mathrm{cm})$} & \multirow{2}{*}{$\begin{array}{l}\text { Standard } \\
\text { deviation } \\
(\mathrm{cm})\end{array}$} \\
\hline & & & maximal & mean & minimal & & first & $\begin{array}{c}\text { second } \\
\text { (median) }\end{array}$ & third & \\
\hline 12 & 25 & 26.80 & 28.30 & 15.72 & 0.00 & 28.30 & 10.00 & 16.00 & 24.00 & 9.12 \\
\hline 15 & 25 & 11.40 & 27.10 & 14.58 & 1.00 & 26.10 & 9.00 & 12.00 & 22.00 & 8.33 \\
\hline 22 & 27 & - & 43.00 & 26.87 & 8.10 & 34.90 & 15.60 & 29.50 & 36.20 & 11.03 \\
\hline 28 & 26 & 23.60 & 37.20 & 21.46 & 8.00 & 29.20 & 14.00 & 22.00 & 27.00 & 8.83 \\
\hline
\end{tabular}

Table 4: $\quad$ Univariate analysis of $x$ distance for different pressure $p$ in pipe.

\begin{tabular}{|c|c|c|c|c|c|c|c|c|}
\hline$p$ & Number of & Mode & \multicolumn{3}{|c|}{$x(\mathrm{~cm})$} & Range & Median & $\begin{array}{c}\text { Standard } \\
(\mathrm{m}\end{array}$ \\
\cline { 4 - 6 } & measurements & $(\mathrm{cm})$ & maximal & mean & minimal & $(\mathrm{cm})$ & $(\mathrm{cm})$ & deviation $(\mathrm{cm})$ \\
\hline 3.25 & 6 & - & 32.00 & 22.00 & 8.00 & 24.00 & 22.00 & 9.17 \\
\hline 3.50 & 7 & 27.50 & 30.20 & 21.86 & 10.10 & 20.10 & 26.00 & 7.93 \\
\hline 3.80 & 7 & 17.50 & 34.00 & 21.57 & 15.00 & 19.00 & 19.00 & 7.07 \\
\hline 4.00 & 8 & - & 55.20 & 32.25 & 7.20 & 48.00 & 38.50 & 19.02 \\
\hline 4.30 & 7 & - & 26.00 & 17.57 & 4.30 & 21.70 & 19.00 & 7.72 \\
\hline 4.50 & 7 & 3.00 & 50.10 & 16.71 & 2.10 & 48.00 & 12.00 & 17.59 \\
\hline 4.80 & 7 & 3.30 & 10.50 & 5.81 & 0.00 & 10.50 & 6.50 & 4.38 \\
\hline 5.00 & 9 & - & 46.20 & 28.40 & 7.00 & 39.20 & 29.40 & 13.10 \\
\hline 5.30 & 10 & 3.10 & 22.00 & 11.33 & 1.00 & 21.00 & 11.00 & 7.78 \\
\hline 5.50 & 11 & - & 19.90 & 9.82 & 3.00 & 16.90 & 10.00 & 5.95 \\
\hline 6.00 & 9 & 23.30 & 41.00 & 20.61 & 2.10 & 38.90 & 22.00 & 11.73 \\
\hline
\end{tabular}


Table 5: $\quad$ Univariate analysis of $y$ distance for different pressure $p$ in pipe.

\begin{tabular}{|c|c|c|c|c|c|c|c|c|}
\hline $\begin{array}{c}p \\
\left(\mathrm{H} \mathrm{H}_{2} \mathrm{O}\right)\end{array}$ & $\begin{array}{c}\text { Number of } \\
\text { measurements }\end{array}$ & $\begin{array}{c}\text { Mode } \\
(\mathrm{cm})\end{array}$ & \multicolumn{3}{|c|}{$y(\mathrm{~cm})$} & Range & Median & $\begin{array}{c}\text { Standard } \\
\text { deviation }(\mathrm{cm})\end{array}$ \\
\hline 3.25 & 6 & 6.70 & 20.00 & 11.08 & 4.10 & 15.90 & 10.50 & 5.99 \\
\hline 3.50 & 7 & 16.00 & 36.30 & 19.59 & 10.00 & 26.30 & 16.00 & 9.06 \\
\hline 3.80 & 7 & 27.10 & 36.00 & 25.64 & 11.00 & 25.00 & 27.00 & 7.78 \\
\hline 4.00 & 8 & 27.50 & 34.00 & 22.94 & 8.00 & 26.00 & 25.00 & 8.19 \\
\hline 4.30 & 7 & 23.30 & 43.20 & 24.71 & 10.20 & 33.00 & 26.00 & 11.44 \\
\hline 4.50 & 7 & 12.90 & 41.00 & 20.71 & 11.90 & 29.10 & 17.00 & 10.52 \\
\hline 4.80 & 7 & - & 36.50 & 18.50 & 9.00 & 27.50 & 15.00 & 9.39 \\
\hline 5.00 & 9 & 13.00 & 31.00 & 16.54 & 8.00 & 23.00 & 14.00 & 7.93 \\
\hline 5.30 & 10 & 22.50 & 28.30 & 20.83 & 14.00 & 14.30 & 21.30 & 5.01 \\
\hline 5.50 & 11 & 24.60 & 29.20 & 19.74 & 5.10 & 24.10 & 24.00 & 8.66 \\
\hline 6.00 & 9 & 8.00 & 30.00 & 14.67 & 2.10 & 27.90 & 12.00 & 9.89 \\
\hline
\end{tabular}

A left asymmetrical distribution was noticed for $x$ data for the pressure of $4.70 \mathrm{~m} \mathrm{H}_{2} \mathrm{O}$ (Tab. 4) and for the pressure of 4.00 and $4.20 \mathrm{~m} \mathrm{H}_{2} \mathrm{O}$ (Tab. 5). In these cases the mode is higher than the median and the median is higher than the mean, which is common for this kind of distribution.

In a case of asymmetrical distribution (right or left), a mode rather than a mean should be treated as a representative value.

Beside asymmetrical, bi- or multimodal distribution of the data was noticed for the $y$ data for the dimension of $22 \mathrm{~mm}$ (Table 3), for the $x$ data for the pressure of 3.45, 4.20, 4.50, 5.20 and $5.70 \mathrm{~m} \mathrm{H}_{2} \mathrm{O}$ (Table 4) and for the $y$ data for the pressure of $5.00 \mathrm{~m} \mathrm{H}_{2} \mathrm{O}$ (Table 5).

For the remaining cases, statistical distributions of the data appeared to be unimodal, but none of them was normal.

The total number of experiments was 111. The water effluence occurred directly over the pipe $(y=0)$ for 4 cases only and $x$ equalled 0 for 7 cases only. Analyzing the localization of all effluences in laboratory experiments it is possible to determine the zone of a probably effluence of water from a place of potential leakage in a water pipe on the ground surface in real conditions.

To determine the zone dimension parallel to the water pipe, tolerance intervals for data $x$ were calculated (Tab. 6). The half of a length of the zone corresponds to the upper tolerance limit, which values appeared to be lower about $1 \mathrm{~cm}$ for the confidence level of $95 \%$ than for the confidence level of $99 \%$, assuming the tolerance level of 70, 75, 80 and $85 \%$. Assuming the tolerance level of $90 \%$, the upper tolerance limit is $7.4 \mathrm{~cm}$ for the confidence level of $99 \%$. The lowest obtained value of an upper tolerance limit $(37.6 \mathrm{~cm})$ denotes that the zone of $2 \times 37.6 \mathrm{~cm}$ in a dimension parallel to the water pipe $(37.6 \mathrm{~cm}$ on each side of the place of leakage) covers at least $70 \%$ possible places of water effluence on the surface, with the confidence level of $95 \%$. In turn, the highest obtained value of an upper tolerance limit $(55.8 \mathrm{~cm})$ denotes that the zone of $2 \times 55.8 \mathrm{~cm}$ in a dimension parallel to the water pipe covers at least $90 \%$ possible places of water effluence on the surface, with the confidence level of $99 \%$. 
Table 6: $\quad$ Tolerance intervals for data $x$.

\begin{tabular}{|c|c|c|c|c|c|}
\hline Tolerance level (\%) & 70 & 75 & 80 & 85 & 90 \\
\hline Confidence level (\%) & \multicolumn{5}{|c|}{95} \\
\hline Upper tolerance limit (cm) & 37.6 & 39.6 & 42.0 & 44.8 & 48.4 \\
\hline Confidence level (\%) & \multicolumn{5}{|c|}{99} \\
\hline Upper tolerance limit (cm) & 38.5 & 40.6 & 43.1 & 46.0 & 55.8 \\
\hline
\end{tabular}

Table 7: $\quad$ Tolerance intervals for data $y$.

\begin{tabular}{|c|c|c|c|c|c|}
\hline Tolerance level (\%) & 70 & 75 & 80 & 85 & 90 \\
\hline Confidence level (\%) & \multicolumn{7}{|c|}{95} \\
\hline Upper tolerance limit (cm) & 33.6 & 35.1 & 36.9 & 39.0 & 41.7 \\
\hline Confidence level (\%) & \multicolumn{5}{|c|}{99} \\
\hline Upper tolerance limit (cm) & 34.3 & 35.9 & 37.7 & 39.9 & 47.2 \\
\hline
\end{tabular}

Analogously, to determine the zone dimension perpendicular to the water pipe, tolerance intervals for data $y$ were calculated (Tab. 7). The lowest and the highest obtained values of an upper tolerance limit equal 33.6 and $47.2 \mathrm{~cm}$, respectively, and their interpretation is the same as in the case of tolerance intervals for data $x$.

Thus, according to our calculation, the zone of leakage should have dimensions of at least $75.2 \mathrm{~cm}$ by $67.2 \mathrm{~cm}$ in the laboratory scale, that correspond to $7.52 \mathrm{~m}$ by $6.72 \mathrm{~m}$ in real conditions. The largest statistically justifiable dimensions of the zone are $111.6 \mathrm{~cm}$ by $94.4 \mathrm{~cm}$, that correspond to $11.16 \mathrm{~m}$ by $9.44 \mathrm{~m}$ in real conditions.

\section{Conclusions}

The laboratory simulation of a failure of a water network pipe was conducted for different pipe diameters and different internal water pressure. During investigations the distance between the place of leakage and the place of water effluence on the soil surface was analyzed, taking into account two directions parallel $(x)$ and perpendicular $(y)$ to the water pipe. The obtained results indicated that there was not dependence between this distance and neither the pipe diameter nor the internal water pressure.

Statistical distributions of $x$ and $y$ data set appeared to be right asymmetrical for a half of analysed cases and none of the rest distributions was found normal, so a mode was treated as a representative value. Different kinds of distributions handicapped statistical analysis.

The effluence of water flowing from the damaged pipe occurred directly over the leakage place rarely during the laboratory investigations, which prompted us to propose creation of a protection area on the soil surface, called a zone of leakage, where effluence of water is possible after a failure of a water network pipe. Dimensions of this zone occurred between $75.2 \mathrm{~cm}$ by $67.2 \mathrm{~cm}$ and $111.6 \mathrm{~cm}$ by $94.4 \mathrm{~cm}$ in the laboratory scale, depending on the statistical assumptions. The obtained results of the investigations enabled to determine the 
secure distance between pipes of a water system and buildings or other infrastructure objects. It is important for the stability of infrastructure objects - a large number of disasters caused by water undermining foundations were reported in the literature.

The obtained results should be treated as initial, reasoning and encouraging to continue the laboratory investigations with lower number of simplifications. We are also going to continue the investigations for in-situ conditions and to elaborate the numerical model of the analyzed problem.

\section{Acknowledgement}

This paper was financed by statutory activity of the Faculty of Environmental Engineering, Lublin University of Technology.

\section{References}

[1] Lambert, A., Water losses management and techniques. Water Science and Technology: Water Supply, 2(4), pp. 1-20, 2002.

[2] Guo, S., Zhang, T., Shao, W., Zhu, D.Z. \& Duan Y., Two-dimensional pipe leakage through a line crack in water distribution systems. J. Zhejiang Univ.-Sci. A (Appl. Phys \& Eng) 14(5), pp. 371-376, 2013.

[3] Ragozin, A.L., Basic principles of natural hazard risk assessment and management. Proc. of the $7^{\text {th }}$ Int. Congress of the International Association of Engineering Geology, eds. Oliveira, R., Rodrigues, L.F., Coehlo, A.G. \& Cunha, A.P., A. A. Balkema: Rotterdam, pp. 1277-1286, 1994.

[4] Khomenko, V.P., Suffosion hazard: today's and tomorrow's problem for cities (Paper 577). Engineering geology for tomorrow's cities. Engineering Geology Special Publication No 22, eds. Culshaw, M.G., Reeves, H.J., Jefferson, I. \& Spink, T.W., Geological Society: London, 2009 (on CD$\mathrm{ROM}$ insert).

[5] Lambert, A. \& Morrison, J.A.E., Recent developments in application of 'bursts and background estimates' concepts for leakage management. Water and Environment Journal, 10, pp. 100-104, 1996.

[6] Buchberger, S. G. \& Nadimpalli, G. Leak estimation in water distribution systems by statistical analysis of flow readings. Journal of Water Resources Planning and Management-ASCE, 130(4), pp. 321-329, 2004.

[7] Eliades, D.G. \& Polycarpou, M.M., Leakage fault detection in district metered areas of water distribution systems. Journal of Hydroinformatics, 14.4, pp. 992-1005, 2012.

[8] Wu, Z., Sage, P. \& Turtle, D., Pressure-dependent leak detection model and its application to a district water system. Journal of Water Resources Planning and Management, 136, 116-128, 2010.

[9] Arsene C.T.C., Gabrys B. \& Al-Dabass D., Decision support system for water distribution systems based on neural networks and graphs theory for leakage detection. Expert Systems with Applications, 39, pp. 13214-13224, 2012. 
[10] Duan, H.F., Lee, P.J., Ghidaoui, M.S. \& Tung, Y., System response function-based leak detection in viscoelastic pipelines. Journal of Hydraulic Engineering, 138(2), pp. 143-153, 2012.

[11] Romano M. \& Kapelan Z., Geostatistical techniques for approximate location of pipe burst events in water distribution systems. Journal of Hydroinformatics, 15.3, pp. 634-635, 2013.

[12] Liu, Z. \& Kleiner, Y., State of the art review of inspection technologies for condition assessment of water pipes. Measurement 46, pp. 1-15, 2013. 